\title{
Diastolic blood pressure achieved at target systolic blood pressure (120-140 mm Hg) and dabigatran-related bleeding in patients with nonvalvular atrial fibrillation: A real-world study
}

\author{
(1) Yu Yu*, (D) Minghui Li*, (D) Wei Zhou**, (D) Tao Wang**, (D) Lingjuan Zhu**, \\ (D) Lihua Hu*, (1) Huihui Bao*, **, (D) Xiaoshu Cheng*,**
}

Departments of *Cardiovascular Medicine, and **Center for Prevention and Treatment of Cardiovascular Diseases, The Second Affiliated Hospital of Nanchang University; Jiangxi-China

\section{ABSTRACT}

Objective: Elevated systolic blood pressure (SBP) can significantly increase the bleeding risk in patients with atrial fibrillation (AF). However, it is unclear whether elevated diastolic blood pressure (DBP), in the presence of well-controlled SBP is also associated with bleeding. Therefore, we aimed to examine the specific relationship between DBP and bleeding in patients with AF treated with anticoagulants and had well-controlled SBP.

Methods: We analyzed data from 542 of 929 patients with nonvalvular AF (NVAF) treated with dabigatran from the Monitor System for the Safety of Dabigatran Treatment study (MISSION-AF) who had a SBP of 120-140 mm Hg at the time of enrollment. The association between DBP and bleeding was analyzed using multivariate logistic regression and smooth curve fitting (penalized spline method). Threshold saturation effect analysis was used to show the nonlinear relationship between DBP and bleeding.

Results: After 3 months of follow-up, 49 bleeding events occurred. Compared with participants with DBP $<80 \mathrm{~mm} \mathrm{Hg}$, those with DBP $\geq 80 \mathrm{~mm}$ $\mathrm{Hg}$ had a $118 \%$ higher bleeding risk [hazard ratio (HR): $2.18 ; 95 \%$ confidence interval (CI): 1.19, 3.98; $p<0.05$ ]. The smooth curve showed a nonlinear relationship between DBP and bleeding risk, and the inflection point of DBP was $80 \mathrm{~mm} \mathrm{Hg}$. When DBP was $\geq 80 \mathrm{~mm} \mathrm{Hg}$, the bleeding risk increased by $59 \%$ (HR: $1.59 ; 95 \% \mathrm{Cl}: 1.16,2.19 ; \mathrm{p}<0.05)$ for every $5 \mathrm{~mm} \mathrm{Hg}$ increase in DBP.

Conclusion: Upon achieving an optimal SBP (120-140 mm Hg), a higher DBP might be associated with a higher bleeding risk in patients with NVAF treated with dabigatran. (Anatol J Cardiol 2020; 24: 267-73)

Keywords: atrial fibrillation, bleeding, blood pressure, dabigatran, hypertension

\section{Introduction}

Epidemiological surveys have shown that approximately 33.59 million patients have atrial fibrillation (AF) worldwide, with a prevalence of approximately $3 \%$; most patients with AF have nonvalvular AF (NVAF) (1,2). Stroke is the most important complication in patients with $A F$, and oral anticoagulants (OACs) can effectively prevent stroke (3). However, taking OACs was often associated with a high bleeding risk among patients with AF (4).

Previous studies have suggested that higher systolic blood pressure (SBP) significantly increases the bleeding risk in patients with $A F(5,6)$. It should be noted that higher SBP often coexists with abnormal diastolic blood pressure (DBP) $(7,8)$. However, to the best of our knowledge, few previous studies have examined the specific relationship between DBP and bleeding risk in the population with AF. Therefore, the association between abnormal $\mathrm{DBP}$ and bleeding risk in patients with $\mathrm{AF}$ is unclear. In addition, previous studies have suggested that the bleeding risk is the lowest when SBP is controlled at $120-140 \mathrm{~mm} \mathrm{Hg}$ (9).

Hence, our study aimed to examine the association between DBP and bleeding risk in the presence of optimal SBP (120-140 $\mathrm{mm} \mathrm{Hg}$ ) among patients with NVAF treated with dabigatran.

\section{Methods}

\section{Subject population and design}

Our current study was a subgroup analysis of the Monitor System for the Safety of Dabigatran Treatment (MISSION-AF)

Address for correspondence: Xiaoshu Cheng, MD, Department of Cardiovascular Medicine, The Second Affiliated Hospital of Nanchang University;

No. 1 Minde Road, Nanchang of Jiangxi, 330006, Jiangxi-China

Phone: +8613607089128 E-mail: xiaoshumenfan126@163.com - huihui_bao77@126.com

Accepted Date: 21.05.2020 Available Online Date: 21.07.2020

(C) Copyright 2020 by Turkish Society of Cardiology - Available online at www.anatoljcardiol.com DOl:10.14744/AnatolJCardiol.2020.11823 
study. More details can be found on the related website (ClinicalTrials.gov Identifier: NCT02414035). Briefly, the MISSION-AF is a large, observational, multicenter, double-blind study. From February 2015 to December 2017, 929 participants were recruited from 12 hospitals throughout China. Details regarding the research population definition, inclusion, and exclusion criteria were discussed in detail in a previously published article (10).

The study was conducted in accordance with the Declaration of Helsinki and was approved by the Ethics Committee of the Second Affiliated Hospital of Nanchang University. Informed written consent was obtained from all patients before they were enrolled in this study.

\section{Data collection}

The exposure variable was mean DBP, defined as the mean value of DBP measured before the bleeding event. Both DBP and SBP were measured thrice using an electronic sphygmomanometer (OMRON; Japan), with a 5-min rest between each measurement. Three consecutive measurements were obtained on the right arm, with 1-min intervals between each measurement. Subsequently, SBP and DBP were calculated as the mean of three independent measurements. The outcome variable was bleeding events that occurred at 3 months of follow-up. In the present study, bleeding events were confirmed based on clinical symptoms, imaging examinations, and laboratory tests, including major and minor bleeding. Major bleeding was defined as (1) fatal bleeding; (2) routine blood tests indicating that hemoglobin is reduced by $>20 \mathrm{~g} / \mathrm{L}$ in a short period of time, or requirement of red blood cell infusion; and (3) symptomatic bleeding in a critical area or organ. Other bleeding events not mentioned previously were defined as minor bleeding $(11,12)$.

The adjusted covariables were as follows: age (years); sex (male, female); body mass index $\left(\mathrm{BMI}, \mathrm{kg} / \mathrm{m}^{2}\right)$; heart rate $(\mathrm{HR}$, bpm); estimated glomerular filtration rate (eGFR, $\left.\mathrm{ml} / \mathrm{min} / 1.73 \mathrm{~m}^{2}\right)$; smoking status (never, former, or current); alcohol consumption status (never, former, or current); AF type (paroxysmal, persistent); radiofrequency ablation; $\mathrm{CHA}_{2} \mathrm{DS}_{2}$-VASc score (congestive heart failure, hypertension, age $\geq 75$ years or between 65 and 74 years, previous stroke or transient ischemic attack, vascular disease, diabetes mellitus, and female sex); HAS-BLED score (hypertension, abnormal renal function, abnormal liver function, age $\geq 65$ years, history of stroke, bleeding, labile INRs, use of other drugs, and concurrent alcohol intake); and past medical history, including hypertension, heart failure (HF), stroke, systemic embolism, and history of medication, such as angiotensin-converting enzyme inhibitors (ACEls), angiotensin receptor blockers (ARBs), calcium channel blockers (CCBs), diuretics, $\beta$-blockers, aspirin, clopidogrel, and warfarin. All of the above covariates were obtained from baseline data.

\section{Follow-up}

Our study data were obtained 1 and 3 months after the patients started taking dabigatran. Information, including routine blood, liver function, and renal function tests, BP measurements, and occurrence of adverse events during the follow-up period, was collected.

\section{Statistical analysis}

Continuous and categorical variables were presented as mean $\pm S D$ and percentage $(\%)$, respectively. We divided the patients into three groups based on a DBP of 70 and $80 \mathrm{~mm} \mathrm{Hg}$, and the baseline characteristics of the study populations were described. First, DBP and bleeding events were used as independent and dependent variables, respectively, in a multivariate logistic regression analysis to assess the relationship between DBP and bleeding. Subsequently, we visually demonstrated the nonlinear relationship between DBP and bleeding through smooth curve fitting (penalized spline method). Furthermore, we accurately identified the curve inflection point by the threshold saturation effect and analyzed the nonlinear relationship between DBP and bleeding in patients with NVAF treated with dabigatran.

All data analyses and form production were performed using the statistical package R (http://www.R-project.org, The R Foundation) and Empower (R) (www.empowerstats.com; X\&Y Solutions, Inc., Boston, MA, USA). When two-tailed $p$ was $<0.05$, the analysis results were considered statistically significant.

\section{Results}

\section{Baseline characteristics of all patients}

The 3-month follow-up period was completed by 929 patients, and this analysis included 542 elderly patients with NVAF (mean age: $65.12 \pm 10.79$ years; $58.49 \%$ men) after excluding patients with $\mathrm{SBP}<120$ and $>140 \mathrm{~mm} \mathrm{Hg}(\mathrm{n}=387)$. Figure 1 shows the inclusion process of the study population. The total number of bleeding events was 49 (including 32 hematuria, 6 gingival bleeding, 6 skin ecchymosis, 3 gastrointestinal bleeding, 1 hemoptysis, and 1 other bleeding case). All bleeding events were minor, and the incidence rate was $9.04 \%$ (49/542). Table 1 shows the baseline

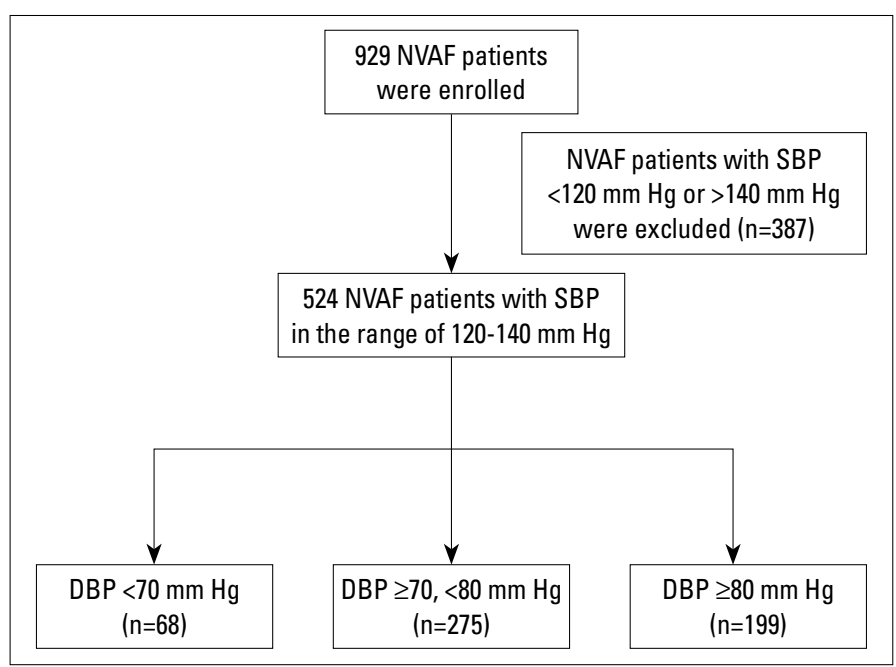

Figure 1. Flow chart of the study patients 
Table 1. Baseline characteristics of all patients stratified by diastolic blood pressure categories

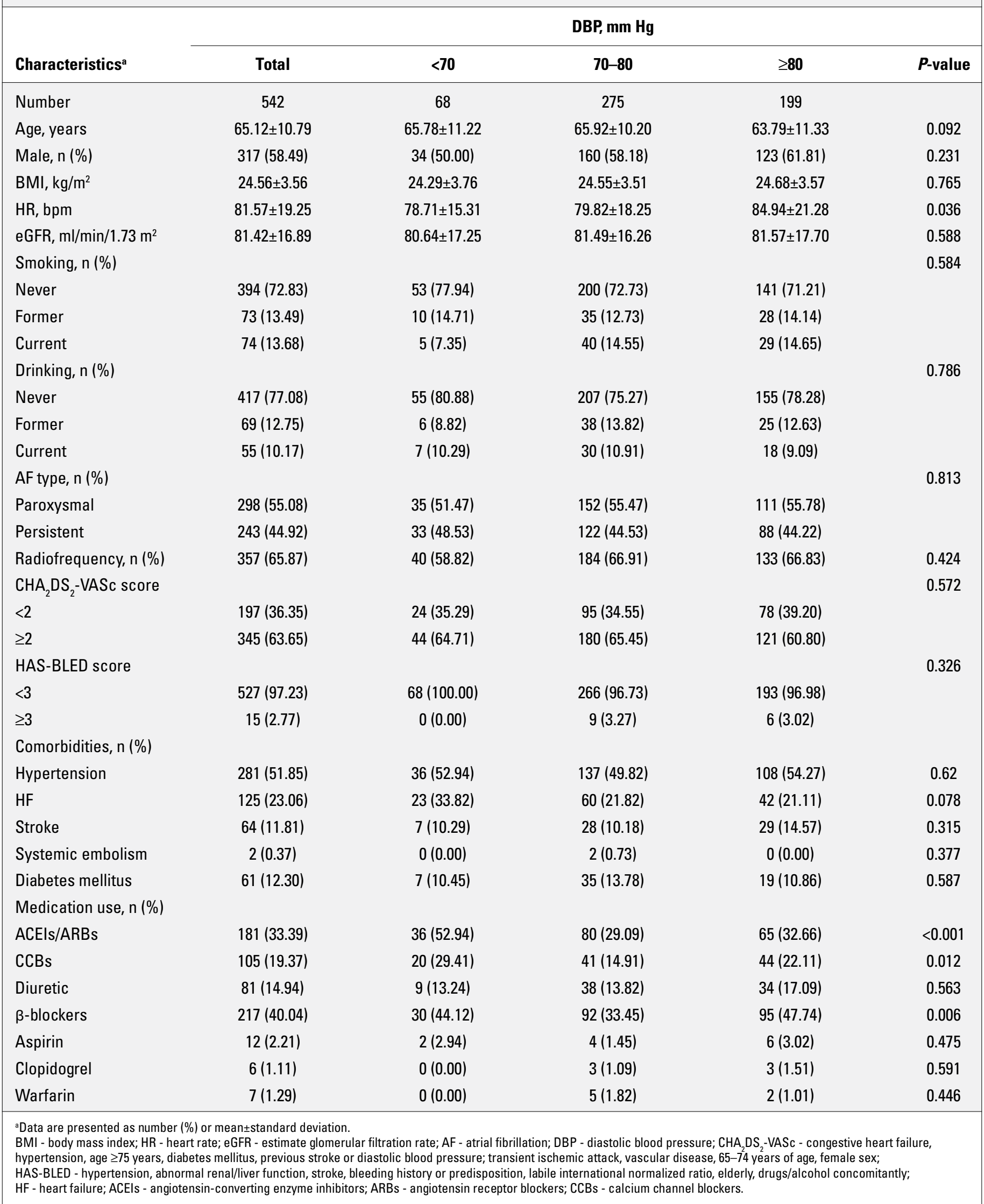


characteristics of patients based on the DBP groups $(<70 \mathrm{~mm}$ $\mathrm{Hg}, 70-80 \mathrm{~mm} \mathrm{Hg}, \geq 80 \mathrm{~mm} \mathrm{Hg}$ ). The following variables were not significantly different between the DBP groups: age, sex, BMI, eGFR, smoking, alcohol consumption, AF type, radiofrequency ablation, $\mathrm{CHA}_{2} \mathrm{DS}_{2}$-VASc score, HAS-BLED score, hypertension, $\mathrm{HF}$, stroke, systemic embolism, diabetes mellitus, and diuretic, aspirin, clopidogrel, and warfarin use (all $p>0.05$ ). The high DBP group ( $\geq 80 \mathrm{~mm} \mathrm{Hg}$ ) had higher $\mathrm{HR}$ and $\beta$-blocker medication rates and lower ACEI/ARB and CCB medication rates (all $p<0.05$ ).

\section{Association between DBP achieved at target SBP (120-140 $\mathrm{mm} \mathrm{Hg}$ ) and bleeding risk}

In this study, we constructed three models for analyzing the independent association between DBP and bleeding in Table 2 . In the fully adjusted model (model 3 ), the bleeding risk increased by $13 \%$ for every $5 \mathrm{~mm} \mathrm{Hg}$ increase in DBP (HR: $1.13 ; 95 \% \mathrm{Cl}$, 0.93-1.38). Subsequently, DBP was converted from a continuous variable to a categorical variable $(<80 \mathrm{~mm} \mathrm{Hg}, 70-80 \mathrm{~mm} \mathrm{Hg}$, $\geq 80 \mathrm{~mm} \mathrm{Hg}$ ) according to clinical experience and literature (13). When the intermediate group $(70-80 \mathrm{~mm} \mathrm{Hg})$ was used as the reference group, the bleeding risk of the lower DBP and higher DBP groups increased by $137 \%$ and $169 \%$, respectively $<<0 \mathrm{~mm}$ Hg; HR: $2.37 ; 95 \% \mathrm{Cl}, 1.17 ; 4.14 ; \geq 80 \mathrm{~mm} \mathrm{Hg} ; \mathrm{HR}, 2.69 ; 95 \% \mathrm{Cl}: 1.38$; 5.28). Because the number of patients with DBP $<70 \mathrm{~mm} \mathrm{Hg}$ was relatively small, we combined the low $(<70 \mathrm{~mm} \mathrm{Hg})$ and medium DBP groups $(70-80 \mathrm{~mm} \mathrm{Hg})$ into a reference group $(<80 \mathrm{~mm} \mathrm{Hg})$. Compared with the reference group $(<80 \mathrm{~mm} \mathrm{Hg})$, the bleeding risk in the high DBP group ( $\geq 80 \mathrm{~mm} \mathrm{Hg}$ ) increased by $118 \%$ (HR: 2.18; $95 \% \mathrm{Cl}: 1.19 ; 3.98, \mathrm{p}<0.05)$.

\section{Nonlinear relationship between DBP and bleeding risk}

Adjusted smooth curve fitting showed that the relationship between DBP and bleeding was nonlinear (Fig. 2). On the left side of the inflection point, the bleeding risk decreased as DBP increased. The bleeding risk increased in individuals with DBP levels on the right side of the inflection point, and the right side of the curve was steeper. We fit the association between DBP and bleeding using the two piecewise binary logistic regression model (Table 3). The $p$ for the log likelihood ratio test was $<0.05$, indicating that the two piecewise binary logistic regression was more suitable for fitting the association between DBP and bleed-

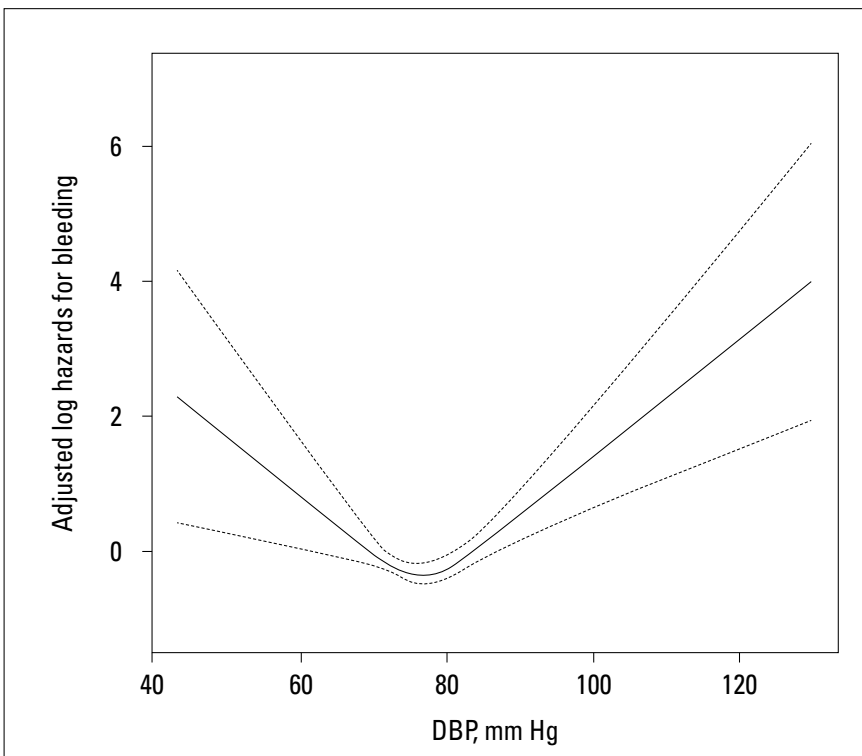

Figure 2. The smooth curve fitting shows a nonlinear association between diastolic blood pressure and bleeding among patients with NVAF treated with dabigatran. Adjusted factors include age, sex, $B M I, H R$, eGFR, smoking, drinking, AF type, radiofrequency ablation, $\mathrm{CHA}_{2} \mathrm{DS}_{2}$-VASc score, HAS-BLED score, hypertension, HF, stroke, systemic embolism, ACEls/ARBs, CCBs, diuretic, $\beta$-blockers, aspirin, clopidogrel, and warfarin

Table 2. Unadjusted and adjusted association between diastolic blood pressure and bleeding

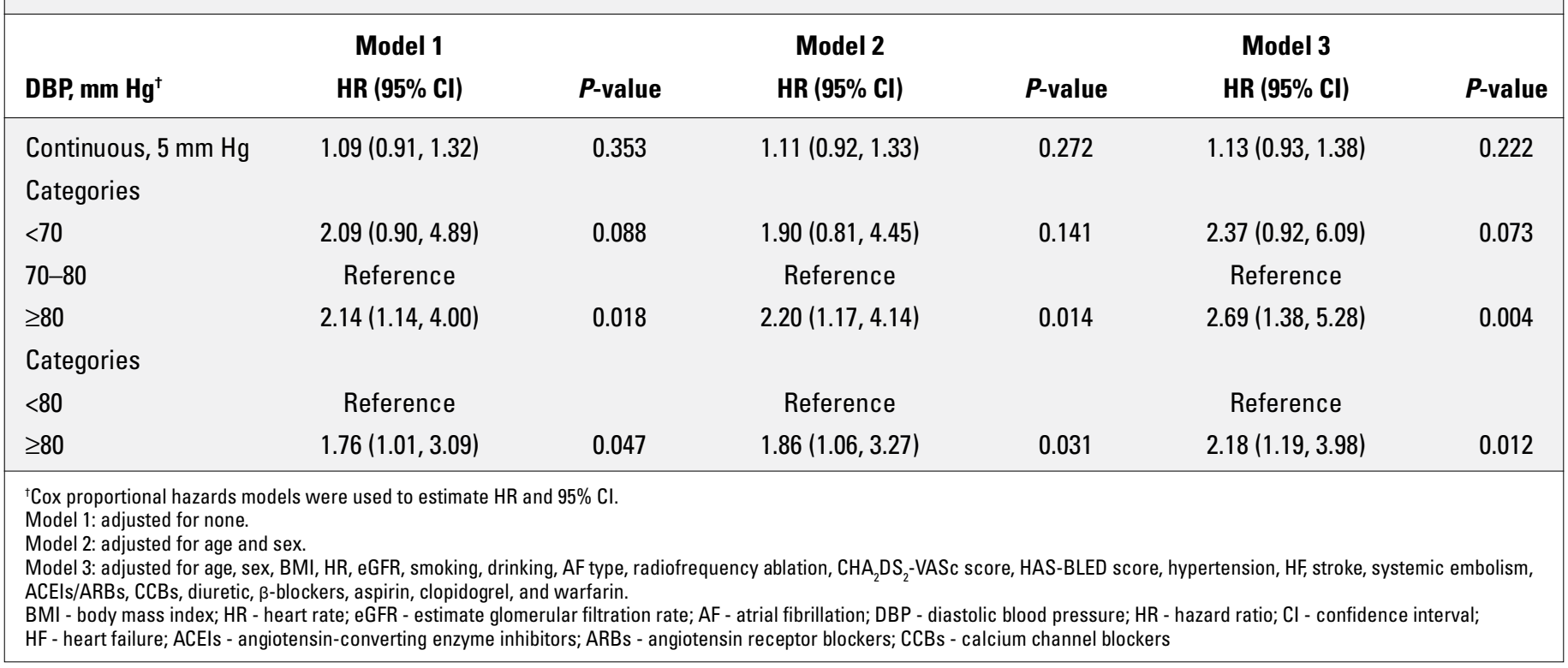


Table 3. Threshold effect analysis of diastolic blood pressure on bleeding

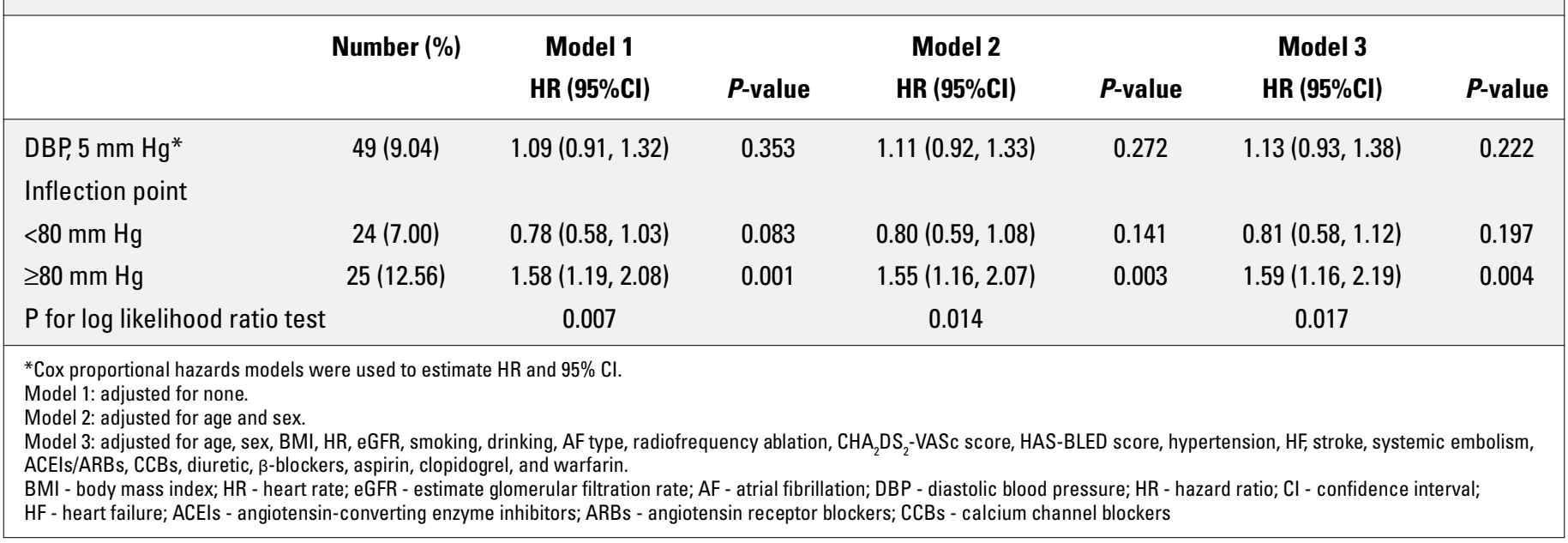

ing. The inflection point of DBP was $80 \mathrm{~mm} \mathrm{Hg}$. The HRs $(95 \%$ Cls) were $0.81(0.58-1.12)$ and $1.59(1.16-2.19)$ on the left and right sides of the inflection point, respectively. The results suggested that bleeding risk increased only with DBP levels on the right of the inflection point (DBP $\geq 80 \mathrm{~mm} \mathrm{Hg}$ ).

\section{Discussion}

This is the first report on the relationship between DBP and bleeding when SBP was controlled within the ideal range $(120$ $140 \mathrm{~mm} \mathrm{Hg}$ ) in patients with NVAF treated with dabigatran. In our study, when the DBP was $80 \mathrm{~mm} \mathrm{Hg}$, it was associated with the lowest bleeding risk. In patients with DBP $<80 \mathrm{~mm} \mathrm{Hg}$, a negative relationship was found between DBP and bleeding risk [HR: 0.81 ; $95 \%$ (CI): $0.58-1.12$ ]. In contrast, when DBP was $\geq 80 \mathrm{~mm}$ $\mathrm{Hg}$, DBP was positively associated with bleeding risk [HR: 1.59; 95\% (CI): 1.16-2.19]. Our findings suggested a nonlinear relationship between DBP and bleeding risk when SBP was controlled at $120-140 \mathrm{~mm} \mathrm{Hg}$ in patients with NVAF treated with dabigatran.

Of note, previous studies have shown that the risk of adverse events was the lowest when SBP was controlled between 120 and $140 \mathrm{~mm} \mathrm{Hg}$ (13). Therefore, when SBP was within this range, an independent effect of DBP on bleeding risk was observed. Consistent with our results, the 2017 ACC/AHA Clinical Practice Guideline for High Blood Pressure indicated that DBP $\geq 80 \mathrm{~mm}$ $\mathrm{Hg}$ was associated with a higher bleeding risk (14). In addition, the HAS-BLED score is widely used to assess the bleeding risk of patients with $A F$, and elevated $S B P(\geq 160 \mathrm{~mm} \mathrm{Hg})$ was one of the risk factors (15-17). Previous studies have also reported that higher SBP increased the bleeding risk of patients with NVAF treated with anticoagulants (5). However, the HAS-BLED score only included elevated SBP as a risk factor and does not consider uncontrolled DBP as a risk factor. Our study suggested that even if SBP was optimal, elevated DBP ( $\geq 80 \mathrm{~mm} \mathrm{Hg}$ ) was associated with a higher bleeding risk in patients with NVAF treated with dabigatran.
Some mechanisms may explain this relationship between $\mathrm{DBP}$ and bleeding risk in the $\mathrm{DBP} \geq 80 \mathrm{~mm} \mathrm{Hg}$ group. A study suggested that DBP increased the bleeding risk possibly through the pathway in which higher DBP impaired endothelial function (18). Another study reported that hypertension increased platelet aggregation and activity, thereby activating the fibrinolytic system, which led to increased bleeding risk (19). A study also found that hypertension was directly related to vascular endothelial lesions, microcirculatory disorders, and modification of the blood coagulation processes (20). In addition, 24 patients had adverse bleeding events in the DBP $<80 \mathrm{~mm} \mathrm{Hg}$ group. However, the association between DBP and bleeding risk was not statistically significant. The negative association between DBP and bleeding risk in the DBP $<80 \mathrm{~mm} \mathrm{Hg}$ group may be because patients with AF treated with anticoagulants inherently had a higher bleeding risk, even if they had a lower BP (21). Therefore, future basic research is needed to explore the mechanism of the relationship between lower DBP and hemorrhage under the effect of anticoagulants.

Of note, most of the bleeding events in our study were minor. Despite this, there are still important clinical implications. First, minor bleeding events are often closely related to major bleeding events (22). In addition, the occurrence of minor bleeding events often interferes with clinical anticoagulant treatment (23). In addition, we used $110 \mathrm{mg}$ dabigatran instead of $150 \mathrm{mg}$ for anticoagulant therapy in our study. The reasons are as follows: first, a previous RE-LY trial confirmed that $110 \mathrm{mg}$ dabigatran was not inferior to $150 \mathrm{mg}$ dabigatran for antithrombotic effects in Asian populations (24). Second, $110 \mathrm{mg}$ dabigatran was selected as the study treatment, considering that $150 \mathrm{mg}$ dabigatran was associated with a higher bleeding risk.

\section{Study limitations}

Some limitations should be noted. First, our study was an observational study; hence, evidence may be insufficient to determine a causal relationship between DBP and bleeding. Second, the study participants were Chinese patients with NVAF, and the 
number of patients was relatively small; thus, the generalizability of the results to other patients with NVAF remained to be verified, and the power calculations were not adequate. Third, our study protocol only included $110 \mathrm{mg}$ dabigatran as an anticoagulant; hence, the study results may not be suitable for patients with NVAF treated with $150 \mathrm{mg}$ dabigatran. Fourth, we did not use 24-h BP monitors to measure BP. In the future, we will combine 24-h BP monitors with the Omron BP monitors. Finally, in the lower DBP group ( $<80 \mathrm{~mm} \mathrm{Hg}$ ), we observed a "strange phenomenon" in which the bleeding risk was reduced with increasing DBP, but the significant difference was not obvious because our sample size was relatively small. Further research is needed to explain the "strange phenomenon" in the future.

Despite these limitations, our study also had advantages. First, we used the mean DBP to reduce the measurement error caused by the inaccurate measurement of BP in patients with NVAF. Second, this "real-world" study was the first to explore the independent association between DBP and the bleeding risk in patients with NVAF treated with dabigatran. In addition, we provided sufficient statistical power to analyze the relationship between DBP and bleeding. Finally, the findings of the study should be helpful for future research enhancing the predictive models of bleeding.

\section{Conclusion}

Our study suggested that even if optimal SBP is achieved (120-140 mm Hg), a higher bleeding risk might be associated with elevated DBP in patients with NVAF treated with dabigatran. The DBP-bleeding risk association was more significant in the $\mathrm{DBP} \geq 80 \mathrm{~mm} \mathrm{Hg}$ group.

Acknowledgment: This study was supported by the Major New Drug Creation Program from the National Science and Technology Major Project (N0.2014ZX09303305) and the Natural Science Foundation of Jiangxi Province (20192BAB205033).

Conflict of interest: None declared.

Peer-review: Externally peer-reviewed.

Authorship contributions: Concept - Y.Y.; Design - Y.Y.; Supervision - H.B., X.C.; Fundings - X.C.; Materials - H.B., X.C.; Data collection and/ or processing - Y.Y., M.L., W.Z., T.W., L.Z., L.H.; Analysis and/or interpretation - Y.Y.; Literature search - H.B., X.C.; Writing - Y.Y.; Critical review - H.B., X.C.

\section{References}

1. Kirchhof $P$, Benussi S, Kotecha D, Ahlsson A, Atar D, Casadei B, et al. 2016 ESC Guidelines for the management of atrial fibrillation developed in collaboration with EACTS. Eur Heart J 2016; 37: 2893962. [CrossRef]
2. Chugh SS, Havmoeller R, Narayanan K, Singh D, Rienstra M, Benjamin EJ, et al. Worldwide epidemiology of atrial fibrillation: a Global Burden of Disease 2010 Study. Circulation 2014; 129: 837-47. [CrossRef]

3. Ruff CT, Giugliano RP, Braunwald E, Hoffman EB, Deenadayalu N, Ezekowitz MD, et al. Comparison of the efficacy and safety of new oral anticoagulants with warfarin in patients with atrial fibrillation: a meta-analysis of randomised trials. Lancet 2014; 383: 955 62. [CrossRef]

4. Lip GY, Lane DA. Bleeding risk assessment in atrial fibrillation: observations on the use and misuse of bleeding risk scores. J Thromb Haemost 2016; 14: 1711-4. [CrossRef]

5. Paciaroni M, Agnelli G, Ageno W, Caso V. Timing of anticoagulation therapy in patients with acute ischaemic stroke and atrial fibrillation. Thromb Haemost 2016; 116: 410-6. [CrossRef]

6. Kodani E, Atarashi H, Inoue H, Okumura K, Yamashita T, Otsuka T, et al. Impact of Blood Pressure Control on Thromboembolism and Major Hemorrhage in Patients With Nonvalvular Atrial Fibrillation: A Subanalysis of the J-RHYTHM Registry. J Am Heart Assoc 2016; 5: e004075.

7. Wei FF, Li Y, Zhang L, Xu TY, Ding FH, Staessen JA, et al. Association of target organ damage with 24-hour systolic and diastolic blood pressure levels and hypertension subtypes in untreated Chinese. Hypertension 2014; 63: 222-8. [CrossRef]

8. Peralta CA, Katz R, Newman AB, Psaty BM, Odden MC. Systolic and diastolic blood pressure, incident cardiovascular events, and death in elderly persons: the role of functional limitation in the Cardiovascular Health Study. Hypertension 2014; 64: 472-80. [CrossRef]

9. Böhm M, Schumacher H, Teo KK, Lonn E, Mahfoud F, Mann JFE, et al. Achieved diastolic blood pressure and pulse pressure at target systolic blood pressure $(120-140 \mathrm{mmHg})$ and cardiovascular outcomes in high-risk patients: results from ONTARGET and TRANSCEND trials. Eur Heart J 2018; 39: 3105-14. [CrossRef]

10. Zhou W, Wang T, Zhu LJ, Wen MH, Hu LH, Huang X, et al. Peripheral leukocyte count and risk of bleeding in patients with non-valvular atrial fibrillation taking dabigatran: a real-world study. Chin Med J (Engl) 2019; 132: 2150-6. [CrossRef]

11. Wallentin L, Yusuf S, Ezekowitz MD, Alings M, Flather M, Franzosi $M G$, et al.; RE-LY investigators. Efficacy and safety of dabigatran compared with warfarin at different levels of international normalised ratio control for stroke prevention in atrial fibrillation: an analysis of the RE-LY trial. Lancet 2010; 376: 975-83. [CrossRef]

12. Kawabata $M$, Yokoyama $Y$, Sasano $T$, Hachiya $H$, Tanaka $Y$, Yagishita $A$, et al. Bleeding events and activated partial thromboplastin time with dabigatran in clinical practice. J Cardiol 2013; 62: 121-6. [CrossRef]

13. Böhm M, Schumacher H, Teo KK, Lonn EM, Mahfoud F, Mann JFE, et al. Achieved blood pressure and cardiovascular outcomes in high-risk patients: results from ONTARGET and TRANSCEND trials. Lancet 2017; 389: 2226-37. [CrossRef]

14. Whelton PK, Carey RM. The 2017 American College of Cardiology/ American Heart Association Clinical Practice Guideline for High Blood Pressure in Adults. JAMA Cardiol 2018; 3: 352-3. [CrossRef]

15. Hart RG, Tonarelli SB, Pearce LA. Avoiding central nervous system bleeding during antithrombotic therapy: recent data and ideas. Stroke 2005; 36: 1588-93. [CrossRef]

16. Pisters $R$, Lane DA, Nieuwlaat $R$, de Vos CB, Crijns HJ, Lip GY. A novel user-friendly score (HAS-BLED) to assess 1-year risk of major bleeding in patients with atrial fibrillation: the Euro Heart Survey. Chest 2010; 138: 1093-100. [CrossRef]

17. Friberg L, Rosenqvist M, Lip GY. Evaluation of risk stratification schemes for ischaemic stroke and bleeding in 182678 patients with 
atrial fibrillation: the Swedish Atrial Fibrillation cohort study. Eur Heart J 2012; 33: 1500-10. [CrossRef]

18. Brandes RP. Endothelial dysfunction and hypertension. Hypertension 2014; 64: 924-8. [CrossRef]

19. Rodrigues SF, Almeida-Paula LD, Granger DN. Synergistic effects of high blood cholesterol and hypertension on leukocyte and platelet recruitment in the cerebral microcirculation. Hypertension 2014; 63: 747-52. [CrossRef]

20. Boiko NV, Shatokhin YV. Pathogenesis of nasal bleeding in the patients presenting with arterial hypertension. Vestn Otorinolaringol 2015; 80: 41-5. [CrossRef]

21. Chen PC, Lip GY, Yeh G, Lin HJ, Chien KL. Risk of bleeding and stroke with oral anticoagulation and antiplatelet therapy in patients with atrial fibrillation in Taiwan: a nationwide cohort study. Plos One 2015; 10: e125257. [CrossRef]
22. Flaker GC, Eikelboom JW, Shestakovska 0, Connolly SJ, Kaatz $S$, Budaj $A$, et al. Bleeding during treatment with aspirin versus apixaban in patients with atrial fibrillation unsuitable for warfarin: the apixaban versus acetylsalicylic acid to prevent stroke in atrial fibrillation patients who have failed or are unsuitable for vitamin K antagonist treatment (AVERROES) trial. Stroke 2012; 43: 3291-7. [CrossRef]

23. Ho MH, Ho CW, Cheung E, Chan PH, Hai JJ, Chan KH, et al. Continuation of dabigatran therapy in "real-world" practice in Hong Kong. PLoS One 2014; 9: e101245. [CrossRef]

24. Eikelboom JW, Wallentin L, Connolly SJ, Ezekowitz M, Healey JS, Oldgren J, et al. Risk of bleeding with 2 doses of dabigatran compared with warfarin in older and younger patients with atrial fibrillation: an analysis of the randomized evaluation of long-term anticoagulant therapy (RE-LY) trial. Circulation 2011; 123: 2363-72. 